\title{
Efficient Structural Characterization of Poly (Methacrylic Acid) by Activated-Electron Photodetachment Dissociation
}

\author{
Marion Girod, ${ }^{1,2}$ Claire Brunet, , ${ }^{1,2,3}$ Rodolphe Antoine, ${ }^{1,2}$ Jérôme Lemoine, , \\ Philippe Dugourd, ${ }^{1,2}$ Laurence Charles ${ }^{4}$
}

${ }^{1}$ Université de Lyon, 69622 Villeurbanne cedex, France

${ }^{2}$ CNRS and Université Lyon I, Laboratoire de Spectrométrie Ionique et Moléculaire, UMR 5579, 43 Bd du 11 Novembre 1918, 69622 Villeurbanne cedex, France

${ }^{3}$ CNRS and Université Lyon I, Institut des Sciences Analytiques, UMR 5380, 43 Bd du 11 Novembre 1918, 69622 Villeurbanne cedex, France

${ }^{4}$ Laboratoire Chimie Provence, Spectrométries Appliquées à la Chimie Structurale, Aix-Marseille University - CNRS, UMR 6264, 13397 Marseille Cedex 20, France

\begin{abstract}
Characterization of end-groups in poly (methacrylic acid) (PMAA) was achieved using tandem mass spectrometry after activated-electron photodetachment dissociation (activated-EPD). In this technique, multiply deprotonated PMAA oligomers produced in the negative-ion mode of electrospray ionization were oxidized into radical anions upon electron photodetachment using a $220 \mathrm{~nm}$ laser wavelength, and further activated by collision. In contrast to conventional collision induced dissociation of negatively charged PMAA, which mainly consists of multiple dehydration steps, fragmentation of odd-electron species is shown to proceed via a radical-induced decarboxylation, followed by reactions involving backbone bond cleavages, giving rise to product ions containing one or the other oligomer termination. A single radical-induced mechanism accounts for the four main fragment series observed in MS/MS. The relative position of the radical and of the anionic center in distonic precursor ions determines the nature of the reaction products. Experiments performed using PMAA sodium salts allowed us to account for relative abundances of product ions in series obtained from PMAA, revealing that ion stability is ensured by hydrogen bonds within pairs of MAA units.
\end{abstract}

Key words: Synthetic polymer, End-group analysis, PMAA, MS/MS, Dissociation pathways, Electron photodetachment

\section{Introduction}

$\mathrm{P}$ olymer end-group analysis by mass spectrometry requires intact ionic adducts generated by soft ionization

Electronic supplementary material The online version of this article (doi:10.1007/s13361-011-0279-5) contains supplementary material, which is available to authorized users.

Correspondence to: Laurence Charles; e-mail: laurence.charles@univ-provence.fr methods to be submitted to dissociation experiments, especially in case of unknown terminations. In most cases, major dissociation reactions of polymeric adducts involve backbone cleavages yielding product ions containing either the initiating or the terminating group. MS/MS data of polymer adducts, most commonly obtained in collision induced dissociation (CID) conditions, should then be analyzed with regards to fragmentation rules established for the targeted polymer family [1]. In some cases, however, collision activation of polymer adducts fails at providing 
useful structural information, as observed for poly(methacrylic acid) (PMAA). Performing electrospray ionization (ESI) either in the negative-ion mode to generate deprotonated molecules [2] or in the positive-ion mode to form alkali adducts [3], we found that CID of PMAA mainly consists of successive eliminations of water between two acidic pendant groups, the so-formed product ions still containing both terminations.

To address challenging cases as encountered for PMAA, the use of alternative ion excitation methods, involving the formation of odd-electron species from multiply charged molecules generated by ESI, might be valuable. Indeed, techniques such as electron transfer dissociation (ETD) [4, 5], electron capture dissociation (ECD) [6], or electron detachment dissociation (EDD) [7] are increasingly applied for biopolymers because they were found to promote cleavage of different bonds as compared to CID. Amongst the few studies reported in the field of synthetic polymers, ECD was found to be particularly useful in the case of poly (ethylene oxide)/poly(propylene oxide) copolymers because it minimized the formation of product ions via rearrangement reactions that often occur in CID and might be misleading for copolymer sequencing [8].

A new method, namely activated-electron photodetachment dissociation (activated-EPD), was recently developed for the gas-phase dissociation of peptide, DNA, and polysaccharide polyanions [9-11]. In this method, radical anions are obtained by electron photodetachment from a multiply deprotonated species. The presence of numerous carboxylic acid groups in PMAA allows both multiply charged oligomers to be easily produced in the negative-ion mode electrospray ionization and absorption capabilities in the $200-250 \mathrm{~nm}$ region [12], thus fulfilling conditions to observe efficient electron photodetachment.

\section{Experimental}

\section{Chemicals}

Poly(methacrylic acid) sodium salt with $M_{\mathrm{n}}=1270 \mathrm{gmol}^{-1}$ and $\mathrm{H}$ atom as both end-groups (Sigma Aldrich, St Louis, MO, USA) was dissolved in Milli-Q water (18.2 M $2 . \mathrm{cm})$, desalted with Amberlite mixed bed resin (Carl Roth, Lauterbourg, France), further diluted using Milli-Q water to a final $10 \mathrm{mg} \mathrm{mL} L^{-1}$ concentration, and introduced in the ionization source at a $5 \mu \mathrm{L} \mathrm{min}{ }^{-1}$ flow rate using a syringe pump. In the case of PMAA sodium salt, the sample was directly diluted to a final $10 \mathrm{mg} \mathrm{mL}^{-1}$ concentration without prior desalting.

\section{Mass Spectrometry}

The experimental setup has been described in details elsewhere [10] and is only briefly presented here. The mass spectrometer is a quadrupole linear ion trap (Thermo Fisher Scientific, San Jose, CA, USA), with a quartz window fitted on the rear of the MS chamber to allow the introduction of the beam from a VIS/UV tunable laser OPO (Optical
Parametric Oscillator). The laser is a nanosecond frequencydoubled tunable Panther EX OPO laser pumped by a Surelite II Nd:YAG laser (both from Continuum, Santa Clara, CA, USA). All EPD experiments were performed at $\lambda=220 \mathrm{~nm}$ (output laser power: $4 \mathrm{~mW}$, repetition rate: $10 \mathrm{~Hz}$ ). The laser beam passes through two diaphragms ( $2 \mathrm{~mm}$ diameter), lenses and a mechanical shutter electronically synchronized with the mass spectrometer, after which it is injected on the axis of the linear trap. Laser irradiation was performed during $5 \mathrm{~s}$. Collisional activation was performed with the same apparatus, at a normalized collision energy of $15 \%-50 \%$ for $30 \mathrm{~ms}$ and using helium gas. The activation $q$ value was set to 0.25 for both CID and activated-EPD experiments. An $m / z$ window of $5 \mathrm{Th}$ was applied for ion precursor isolation for both methods.

\section{Results and Discussion}

Both singly and doubly deprotonated PMAA oligomers could be generated in the negative-ion mode ESI. When subjected to laser irradiation (50 laser shots) at $220 \mathrm{~nm}$, doubly charged PMAA oligomers undergo charge reduction followed by elimination of $\mathrm{CO}_{2}$. As exemplified for the case of $\left[\mathrm{M}_{13}-2 \mathrm{H}\right]^{2-}$ at $m / z 559.4$ in Figure $\mathrm{S} 1$, the oxidation product $\left[\mathrm{M}_{\mathrm{n}}-2 \mathrm{H}\right]^{\cdot}$ expected at $m / z 1118.8$ was hardly observed in EPD spectra and would instead readily decarboxylate to a radical quaternary carbon in the soformed $\mathrm{m} / \mathrm{z} 1074.3$ ion. Activated-EPD experiments would thus consist of activating $\left[\mathrm{M}-2 \mathrm{H}-\mathrm{CO}_{2}\right]^{-\bullet}$ via collisions.

As reference data, CID of $\left[\mathrm{M}_{13}-\mathrm{H}\right]^{-}$at $\mathrm{m} / z 1119.4$ is presented in Figure $\mathrm{S} 2$ and indicates that up to six successive dehydration steps have occurred, consistently with dissociation rules established for PMAA in the negative-ion mode [2]. In contrast to these poorly informative data, activated-EPD of doubly charged PMAA oligomers generates multiple abundant ions (Figure 1). Five product ion series (Table 1), in which consecutive ions are spaced by $86 \mathrm{Da}$, could be accounted for by considering different forms of the $\left[\mathrm{M}_{13}-2 \mathrm{H}-\mathrm{CO}_{2}\right]^{-}$ precursor ion, based on relative positions of the radical carbon and the remaining deprotonated acidic group.

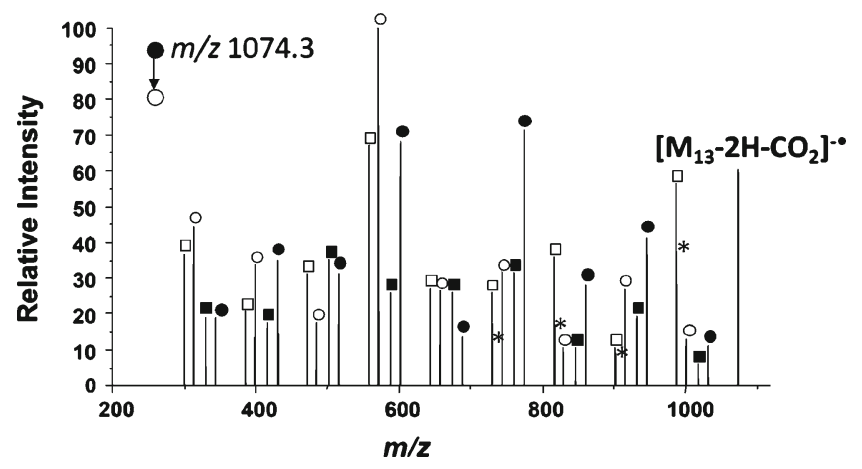

Figure 1. Activated-electron photodetachment dissociation spectrum of the $\left[\mathrm{M}_{13}-2 \mathrm{H}-\mathrm{CO}_{2}\right]^{-\bullet}$ ion $(\mathrm{m} / z$ 1074.3) under a normalized CID collision energy of $25 \%$ for $30 \mathrm{~ms}$, showing the formation of $a_{i}^{-}$(open circles), $b_{i}^{-\bullet}$ (filled circles), $y_{i}^{-}$(open squares), $\mathrm{z}_{\mathrm{i}}^{-}$(filled squares), and $\left(\mathrm{b}_{\mathrm{i}}^{-}\right)^{\prime}$ (stars) product ions. 
Table 1. Structure, Nomenclature and $m / z$ Ratio of Product Ions Detected in MS/MS Upon Activated-EPD of PMAA (X=H) and Sodiated PMAA (X=Na). In Figures 1 and 2

\begin{tabular}{|c|c|}
\hline Label* / Nomenclature / Structure & Product ions \\
\hline 0 & $\begin{array}{l}-\mathrm{X}=\mathrm{H} \text { in } \mathrm{M}_{13}, i=3-11: \\
m / z 313,399,485,571,657,743,829,915,1001 \\
-\mathrm{X}=\mathrm{Na} \text { in } \mathrm{M}_{11}^{\prime}, i=7-9: \\
m / z \text { 789, 897, } 1005\end{array}$ \\
\hline $\mathbf{b}_{\mathrm{i}}^{-{ }^{-}}$ & $\begin{array}{l}-\mathrm{X}=\mathrm{H} \text { in } \mathrm{M}_{13}, i=4-12: \\
m / z \text { 344, 430, 516, 602, 688, 774, 860, 946, } 1032 \\
-\mathrm{X}=\mathrm{Na} \text { in } \mathrm{M}_{11}^{\prime}, i=6-10: \\
m / z 626,734,842,950,1058\end{array}$ \\
\hline$\square$ & $\begin{array}{l}-\mathrm{X}=\mathrm{H} \text { in } \mathrm{M}_{13}, i=3-11: \\
m / z 299,385,471,557,643,729,815,901,987 \\
-\mathrm{X}=\mathrm{Na} \text { in } \mathrm{M}^{\prime}{ }_{11}, i=5-9 \\
m / z \text { 559, } 667,775,883,991\end{array}$ \\
\hline$z_{i}^{-\bullet}$ & $\begin{array}{l}-\mathrm{X}=\mathrm{H} \text { in } \mathrm{M}_{13}, i=3-11: \\
m / z 330,416,502,588,674,760,846,932,1018 \\
-\mathrm{X}=\mathrm{Na} \text { in } \mathrm{M}_{11}^{\prime}, i=5-9: \\
m / z 612,720,828,936,1044\end{array}$ \\
\hline$\left(\mathbf{b}_{\mathrm{i}}^{-\bullet}\right.$ & $\begin{array}{l}-\mathrm{X}=\mathrm{H} \text { in } \mathrm{M}_{13}, i=8-11: \\
m / z 730,816,902,988 \\
-\mathrm{X}=\mathrm{Na} \text { in } \mathrm{M}_{11}^{\prime}, i=5-9: \\
m / z 560,668,776,884,992\end{array}$ \\
\hline
\end{tabular}

Two product ion series would arise from dissociation of those precursor ions with a radical carbon located between the deprotonated MAA unit and the $\omega$ end-group. When radical-induced $\mathrm{C}-\mathrm{C}$ bond homolysis occurs in the righthand part of the polymeric backbone (Scheme S1), a neutral containing the $\omega$ end-group would be formed together with a distonic radical anion containing the $\alpha$ initiating group (annotated with filled circles in Figure 1). According to Wesdemiotis et al.'s nomenclature [1], these product ions should be called $\mathrm{b}_{\mathrm{i}}{ }^{-}$, with $i$ the number of complete (neutral 
or deprotonated) monomers they contain. This ion series includes all congeners from $b_{4}{ }^{-}$to $b_{12}{ }^{-}$, which could either be formed directly from the $\mathrm{m} / \mathrm{z} 1074.3$ ion with different locations for the radical carbon, or according to a radicalinduced depolymerization process of higher $b_{i}^{-\bullet}$ homologues (Scheme S1). Alternatively, the same mechanism could induce the homolysis of a $\mathrm{C}-\mathrm{C}$ bond in the left-hand part of the polymeric skeleton (Scheme S1), generating $\mathrm{a}_{\mathrm{i}}^{-}$product ions, with $i=3-11$ and annotated by open circles in Figure 1, upon the release of radical species containing the $\omega$ end-group.

Similarly, the same radical-induced mechanism could account for two other product ion series, namely $\mathrm{y}_{\mathrm{i}}^{-}$and $\mathrm{z}_{\mathrm{i}}{ }^{-}$, starting from $\mathrm{m} / \mathrm{z} 1074.3$ precursors where the radical carbon is located between the deprotonated MAA unit and the $\alpha$ end-group. When the cleaved $\mathrm{C}-\mathrm{C}$ bond is at the left of the radical center, the $\mathrm{y}_{\mathrm{i}}^{-}$ion series would be formed, as observed with $i=3-11$ for peaks annotated by open squares in Figure 1. Alternatively, distonic radical anions $\mathrm{z}_{\mathrm{i}}^{-}$(with $i=$ 3-11 and annotated by filled squares in Figure 1) would arise from cleavage of the $\mathrm{C}-\mathrm{C}$ bond at the right of the radical center, after elimination of a neutral containing the $\alpha$ end-group. Owing to the location of the radical, these $z_{i}{ }^{\cdot}$ ions could further experience a depolymerization process, accounting for all lower homologues in the series.

Finally, the last series of product ions measured at $\mathrm{m} / \mathrm{z}$ 988.1, 902.1, 816.6, and 730.0 (annotated with stars in Figure 1) would be formed after the activated $\mathrm{m} / \mathrm{z} 1074.3$ ion has released one to four MAA units, respectively. This process would occur after migration of a terminal $\mathrm{H}$ to the radical carbon (Scheme S2) and would generate $\left(b_{i}^{-0}\right)^{\prime}$ ions. Different transfers of $\mathrm{H}^{\bullet}$ involving folding of the polymeric chain must be envisaged to allow radical migration to the chain end to initiate the depolymerization process, and such rearrangement might well limit the kinetics of the process, thus accounting for the limited number of congeners within this series $(i=8-11)$.

Interestingly, the nature of major ion in all main series (i.e., $\mathrm{a}_{6}^{-}, \mathrm{y}_{6}^{-}, \mathrm{b}_{7}{ }^{\bullet}$ and $\mathrm{z}_{5}{ }^{-}$) suggests a preferential location of the radical on the central monomer in the $m / z 1074.3$ activated ion. Considering conformation adopted by PMAA chains upon multiple charging [13], we conclude that the polymer chain must be large enough so that neutral monomers can efficiently "solvate" the first deprotonated MAA unit in order to stabilize the increase in Coulomb repulsions arising from inclusion of an additional charge. At least five MAA units should be involved in both the coordination sphere of one negative charge and the linking domain that spares the next "solvated" deprotonated monomer. As a result, the central monomer of the chain would reside in the linking domain but, as the studied PMAA oligomers are quite small, this central monomer would also be in close proximity of both $\mathrm{COO}^{-}$groups. Once one carboxylate group has been oxidized upon laser irradiation, it is reasonable to assume that this proximity would allow the radical to migrate to the central unit, via different transfers of $\mathrm{H}^{\bullet}$ from neutral $\mathrm{COOH}$ groups to the oxidized $\mathrm{COO}^{\bullet}$ moiety.

It was also observed that distonic radical anion products containing an even number of neutral MAA were systemati- cally more abundant than their adjoining congeners holding an odd number of pendant $\mathrm{COOH}$ groups. This effect was assigned to the ability of two consecutive neutral MAA to interact via hydrogen bonding, thus increasing the overall stability of the ion [2]. For example, $\mathbf{b}_{9}{ }^{\bullet}$ at $\mathrm{m} / \mathrm{z} 774.2$ contains four MAA pairs in which pendant $\mathrm{COOH}$ moieties would be in strong interaction, and is more abundant than both $\mathrm{b}_{8}{ }^{\bullet}$ at $m / z$ 688.1 and $\mathrm{b}_{10} \bullet$ at $m / z$ 860.4, in which there is a lone neutral MAA monomer. Furthermore, $b_{9}{ }^{-\cdot}$ would more readily eliminate a neutral consisting of two hydrogen-bonded MAA monomers than release a single MAA unit. This would account for the higher abundance measured for $\mathrm{b}_{7}{ }^{\bullet}$ at $\mathrm{m} / \mathrm{z} 602.1$ compared with $b_{8}{ }^{\bullet}$ (Figure 1). Similar conclusions could be reached for $\mathrm{z}_{\mathrm{i}}^{\bullet}$ product ions. To probe this hydrogen-bond stabilization assumption, the same EPD experiments were conducted on a PMAA sodium salt (further called $\mathrm{M}^{\prime}$ ).

The mass spectrum obtained after UV excitation of the doubly desodiated 11-mer is shown in the inset of Figure 2. $\left[\mathrm{M}_{11}^{\prime}-2 \mathrm{Na}\right]^{-\bullet}$ could be isolated for further activation, which mainly led to the formation of $\left[\mathrm{M}_{11}^{\prime}-2 \mathrm{Na}-\mathrm{CO}_{2}\right]^{-*}$. In contrast to the case of deprotonated PMAA, EPD performed on di-anions of PMAA sodium salt provides an evidence that decarboxylation may be prompted by prior electron loss on the charged carboxylic group, as already observed for peptides $[10,14]$. Collisional activation of $\left[\mathrm{M}_{11}^{\prime}-2 \mathrm{Na}-\right.$ $\left.\mathrm{CO}_{2}\right]^{-\bullet}$ resulted in four main series of product ions spaced by $108 \mathrm{Da}$ (Figure 2). Fragmentation rules previously established for activated EPD of $\left[\mathrm{M}_{\mathrm{n}}-2 \mathrm{H}-\mathrm{CO}_{2}\right]^{-\bullet}$ were found to also apply here, and assignments of product ion series are presented in Table 1. Two additional product ion series were observed but were found to be poorly informative as they were internal fragments (Schemes S3 and S4).

In contrast to MS/MS results obtained for PMAA (Figure 1), only the highest congeners were observed in

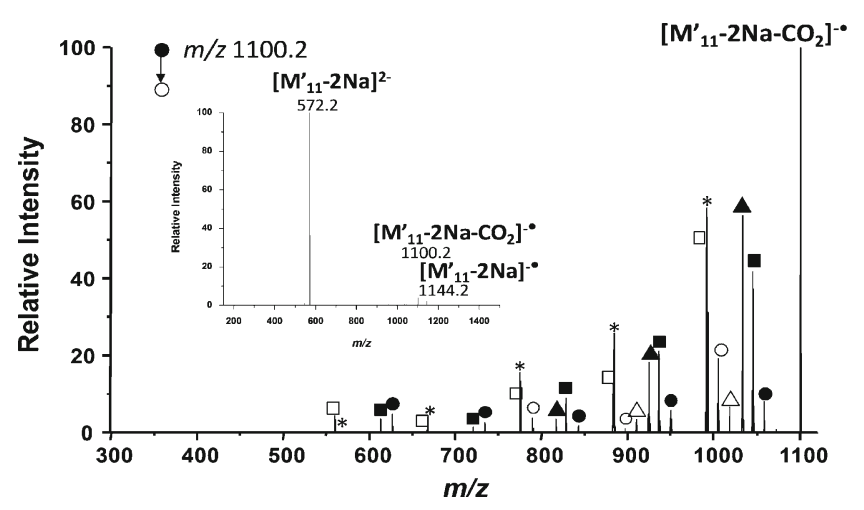

Figure 2. Activated-electron photodetachment dissociation spectrum of the $\left[\mathrm{M}^{\prime}{ }_{11}-2 \mathrm{Na}-\mathrm{CO}_{2}\right]^{-\bullet}$ ion $(\mathrm{m} / \mathrm{z}$ 1100.2) under a normalized CID collision energy of $20 \%$ for $30 \mathrm{~ms}$, showing the formation of $a_{i}^{-}$(open circles), $b_{i}^{-\bullet}$ (filled circles), $y_{i}^{-}$(open squares), $\mathrm{z}_{\mathrm{i}}^{-\bullet}$ (filled squares), and ( $\left.\mathrm{b}_{\mathrm{i}}^{-{ }^{-}}\right)^{\prime}$ (stars) product ions. Filled and open triangles designate internal fragments described in supplemental information. Inset: electron photodetachment spectrum of the doubly desodiated PMAA 11mer $(\mathrm{m} / z$ 572.2) under 50 laser shots at $220 \mathrm{~nm}$. 
each major product-ion series $\left(\mathrm{a}_{7-9}{ }^{-}, \mathrm{b}_{6-10^{-}}, \mathrm{y}_{5-9}{ }^{-}\right.$, and $\left.\mathrm{z}_{5-9}{ }^{-\bullet}\right)$. In particular, $\mathrm{b}_{\mathrm{i}}^{-{ }^{-}}$and $\mathrm{z}_{\mathrm{i}}^{-\boldsymbol{\bullet}}$ distonic radical anions do not display any particular stability as a function of the parity of their polymerization degree. This result would be in favor of the hydrogen bond assumption proposed to stabilize some product ions of $\left[\mathrm{M}_{\mathrm{n}}-2 \mathrm{H}-\mathrm{CO}_{2}\right]^{\bullet}$. Moreover, no base peak indicating a preferential location of the radical on a central monomer in $\left[\mathrm{M}^{\prime}{ }_{11}-2 \mathrm{Na}-\mathrm{CO}_{2}\right]^{\bullet}$ was observed: migration of $\mathrm{Na}$ required to allow such a structure for the $m / z 1100.2$ precursor ion is indeed hard to envisage.

In summary, in contrast to CID of even-electron PMAA ionic species that are poorly informative, all dissociation processes observed upon activated-EPD of PMAA involve homolytic bond cleavages of the oligomer backbone, allowing a clear characterization of each end-group. While the mass of the $\alpha$ group can be obtained from the analysis of both $\mathrm{a}_{\mathrm{i}}^{-}$and $\mathrm{b}_{\mathrm{i}}{ }^{-}$ product ions, the mass of the terminating $\omega$ moiety can be determined from $\mathrm{m} / \mathrm{z}$ values measured for both $\mathrm{y}_{\mathrm{i}}^{-}$and $\mathrm{z}_{\mathrm{i}}^{-}$ fragments. An additional advantage of this approach is the production of abundant product ions throughout each series, allowing mass data sets to be obtained for each end-group from unambiguous $m / z$ value measurements.

\section{References}

1. Wesdemiotis, C., Solak, N., Polce, M.J., Dabney, D.E., Chaicharoen, K., Katzenmeyer, B.C.: Fragmentation Pathways of Polymer Ions. Mass Spectrom. Rev. 30, 523-559 (2011)

2. Giordanengo, R., Viel, S., Allard-Breton, B., Thevand, A., Charles, L. Tandem Mass Spectrometry of Poly(Methacrylic Acid) Oligomers
Produced by Negative Mode Electrospray Ionization. J. Am. Soc. Mass Spectrom. 20, 25-33 (2009)

3. Giordanengo, R., Viel, S., Allard-Breton, B., Thevand, A., Charles, L.: Positive Mode Electrospray Tandem Mass Spectrometry of Poly (Methacrylic Acid) Oligomers. Rapid Commun. Mass Spectrom. 23, 1557-1562 (2009)

4. Syka, J.E.P., Coon, J.J., Schroeder, M.J., Shabanowitz, J., Hunt, D.F.: Peptide and Protein Sequence Analysis by Electron Transfer Dissociation Mass Spectrometry. Proc. Natl. Acad. Sci. U.S.A. 101, 9528-9533 (2004)

5. Pitteri, S.J., Chrisman, P.A., McLuckey, S.A.: Electron-Transfer Ion/Ion Reactions of Doubly Protonated Peptides: Effect of Elevated Bath Gas Temperature. Anal. Chem. 77, 5662-5669 (2005)

6. Zubarev, R.A.: Reactions of Polypeptide Ions with Electrons in the Gas Phase. Mass Spectrom. Rev. 22(1), 57-77 (2003)

7. Budnik, B.A., Haselmann, K.F., Zubarev, R.A.: Electron Detachment Dissociation of Peptide Dianions: An Electron-Hole Recombination Phenomenon. Chem. Phys. Lett. 342, 299-302 (2001)

8. Cerda, B.A., Horn, D.M., Breuker, K., McLafferty, F.W.: Sequencing of Specific Copolymer Oligomers by Electron-Capture-Dissociation Mass Spectrometry. J. Am. Chem. Soc. 124, 9287-9291 (2002)

9. Gabelica, V., Tabarin, T., Antoine, R., Rosu, F., Compagnon, I., Broyer, M., De Pauw, E., Dugourd, P.: Electron Photodetachment Dissociation of DNA Polyanions in a Quadrupole Ion Trap Mass Spectrometer. Anal. Chem. 78, 6564-6572 (2006)

10. Larraillet, V., Antoine, R., Dugourd, P., Lemoine, J.: Activated-Electron Photodetachment Dissociation for the Structural Characterization of Protein Polyanions. Anal. Chem. 81, 8410-8416 (2009)

11. Racaud, A., Antoine, R., Dugourd, P., Lemoine, J.: Photoinduced Dissociation of Heparin-Derived Oligosaccharides Controlled by Charge Location. J. Am. Soc. Mass Spectrom. 21, 2077-2084 (2010)

12. Szyper, M., Zuman, P.: Electronic Absorption of Carboxylic-Acids and Their Anions. Anal. Chim. Acta 85, 357-373 (1976)

13. Trimpin, S., Plasencia, M., Isailovic, D., Clemmer, D.E.: Resolving Oligomers from Fully Grown Polymers with IMS-MS. Anal. Chem. 79, 7965-7974 (2007)

14. Antoine, R., Joly, L., Tabarin, T., Broyer, M., Dugourd, P., Lemoine, J.: Photo-Induced Formation of Radical Anion Peptides. Electron Photodetachment Dissociation Experiments. Rapid Commun. Mass Spectrom. 21, 265-268 (2007) 